\title{
The Effect of Cationic Polyacrylamide as Retention Aid for Alkaline Papermaking
}

\author{
Nina Elyani* ${ }^{*}$ Lies Indriati \\ Center for Pulp and Paper, Jl. Raya Dayeuhkolot no.132 Bandung 40258, Indonesia
}

\begin{abstract}
Alkaline paper has advantages in their high shelf life (permanence) compared to paper made in acidic conditions. The conversion from acidic papermaking process to alkaline process is a major change experienced by the paper industry. In alkaline papermaking, one of the internal sizing agent used is Alkylketene Dimer (AKD). This additive is used to improve the resistance of paper to liquid penetration. Changes to the use of sizing agents are also followed by other changes; one of them is the change in the retention aids used. The use of Cationic Polyacrylamide (C-PAM) as retention aid on alkaline papermaking which is sized by AKD has been investigated. In this study, $100 \%$ Leaf Bleached Kraft Pulp (LBKP) as a fiber source was refined in a laboratory beater up to $400 \mathrm{mLCSF}$ of freeness and then mixed with paper additives i.e. $0.1 \%$ AKD as sizing agent, $15 \%$ calcium carbonate as filler and $1 \%$ cationic starch as dry strength agent. The addition of C-PAM was varied in the range of $0 \%-0.4 \%$ based on dry weight of fiber. After being mixed thoroughly, the handsheets of $60 \mathrm{~g} / \mathrm{m} 2$ grammage were made and then tested for tensile strength and water absorption (Cobb-60). The addition of 0.1\% C-PAM resulted paper with good tensile strength and improved the resistance to liquid penetration.
\end{abstract}

Keywords: Alkaline paper, AKD sizing, C-PAM, tensile strength, water absorption (Cobb-60)

DOI: $10.7176 / \mathrm{CMR} / 12-6-04$

Publication date:July $31^{\text {st }} 2020$

\section{Introduction}

In papermaking, about $70 \%$ up to $100 \%$ of materials used is cellulose fibers. The rest are paper chemicals as an additives which has an important role in development of paper properties. Basically, one of cellulose characteristics is hydrophilic and as the main raw material in paper, this property will affect mostly the properties of paper produced, particularly the water absorptivity of paper. Except kinds of paper used to absorb liquid such as tissue papers, etc. almost all papers should have low water absorptivity, both for printing-writing papers and packaging papers. To control this paper property, internal sizing agent is added to the mixture of cellulose fibers and other additives such as fillers and retention aids, to reduce the rate of liquid penetration into paper.

Besides improving the resistance of paper to liquid penetration, internal sizing improves paper printability as well by controlling ink absorption and spreading, and reducing the effect of aqueous fountain solution on loss of paper strength (Evans, 1989; Neimo, 1999).

Based on the $\mathrm{pH}$ conditions, the papermaking process is divided into acidic, neutral and alkaline processes. The $\mathrm{pH}$ of paper stock is determined by the internal chemical sizing used. The acid process is a traditional internal sizing process based on rosin and alum that has been known for a long time (Hubbe, 2005). Acidic pH conditions on paper affect mainly the permanence or durability of paper, thus causing the industry switch their papermaking process to a neutral or even alkaline process.

The new neutral and alkaline internal sizing have been found to be more efficient compared to acid internal sizing using rosin size due to its better hydrophobicity and lesser size reversion, as well as better durability of paper produced (Lee and Luner, 2005, Song et al., 2012).

Conversion of papermaking process from acidic conditions to neutral or alkaline $\mathrm{pH}$ conditions affects the use of other paper chemicals, including the retention aids used. Retention aids is one of paper chemical which serves to increase the retention of solids in paper. A lot of investigations have been done regarding the use of retention aid in alkaline papermaking. This paper will report the used of cationic polyacrylamide (C-PAM) as a retention aid in alkaline papermaking using alkylketene dimer (AKD) as sizing agent.

\subsection{Alkylketene Dimer (AKD)}

Alkylketene dimer (AKD) is an internal sizing agents that have been widely used by the paper industry. It is particularly effective in alkaline papermaking system. Alkaline papermaking provides the benefits of a stronger and smoother sheet, and improved paper permanence. Alkaline paper is suitable for archival purposes.

The mechanism of AKD retention is the combination with negative charge on the surface of the fiber. Figure 1 shows the reaction of AKD with $\mathrm{OH}$ group at fiber surfaces. 


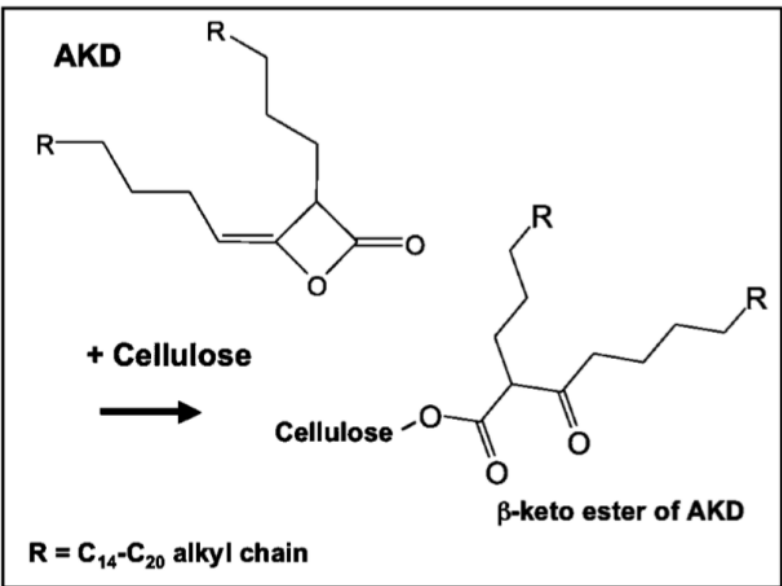

Figure 1. Reaction between AKD and fiber surfaces (Hubbe, 2005)

A study by Isogai et al. (1997) reported that deposition or retention of AKD can be prevented by blocking carboxyl groups in the pulp with non-ionic methylamide groups. This is clear evidence that the degree of surface charge on pulp fibers affects the sizing performance of AKD.

In order to be distributed evenly and retained to the maximum extent possible on paper sheets, the use of $\mathrm{AKD}$ is generally accompanied by the addition of cationic polymers (Hubbe, 2005). Therefore, the use of AKD as internal sizing agent should be combined with cationic retention aid.

\subsection{Cationic Polyacrylamide (C-PAM)}

In general, retention aids in papermaking is a very high molecular-weight and water-soluble polymers that are added to cellulosic fiber slurries before the formation of paper in order to improve the retention of fine particles in paper, including cellulosic fines.

Cationic polyacrylamide (C-PAM) as retention and drainage aid to the pulp in addition to fill all kinds of additives have a good retention effect, has a wide range of applications (Jin et al. 2003, Shan et al. 2012). C-PAM with positive charge can effectively neutralize the negative charge of the surface of the pulp (Vanerek et al. 2000), in the fiber and filler in the directional arrangement of macromolecular structure, therefore, a gap channel is formed to help improve the effect of intervention.

The effect of C-PAM on AKD and filler retention is obvious, so it has been widely used. C-PAM could significantly increase tensile strength. The amount of C-PAM added in this study are varied in the range of $0 \%$ $0.4 \%$ basedon oven dried weight of pulp.It was added during stock preparation.

The $\mathrm{pH}$ of paper stock after AKD and calcium carbonate addition should be maintained between $7.5-8.5$ (Jeremo M. Gess and Paul H. Wilson 2007).

\section{Experimental}

\subsection{Materials}

The materials used in this study were leaf bleached kraft pulp (LBKP), alkylketene dimer (AKD), calcium carbonate $\left(\mathrm{CaCO}_{3}\right)$, cationic starch and cationic polyacrylamide (C-PAM).

The equipment used including analytical balance, drying oven, dish, desiccator, measuring glass, glassware, Niagara beater, freeness tester, agitator,drying plate, crus tang, and paper testing equipment i.e. pH-meter, Cobb sizetester and tensile tester.

\subsection{Methods}

The laboratory experiments were carried out as described below.

LBKP were refined using Niagara beater up to $400 \mathrm{~mL}$ CSF. The freeness of pulp was determined using Canadian Standard Freeness (CSF) tester and then the $15 \%$ of calcium carbonate, $0.1 \%$ of AKD, $1 \%$ of cationic starch and then C-PAM with dosages of $0.0 \%-0.4 \%$ added into the fiber furnish. The addition of all additives were based on dry basis of fiber.

The handsheets of $60 \mathrm{~g} / \mathrm{m} 2$ were made, and then pressed and dried. The handsheets resulted were then tested for $\mathrm{pH}$, tensile strength and Cobb size. Before being tested, the handsheets were conditioned for 24 hours in a room with the temperature and relative humidity of $23+1{ }^{\circ} \mathrm{C}$ and $50+2 \%$. 


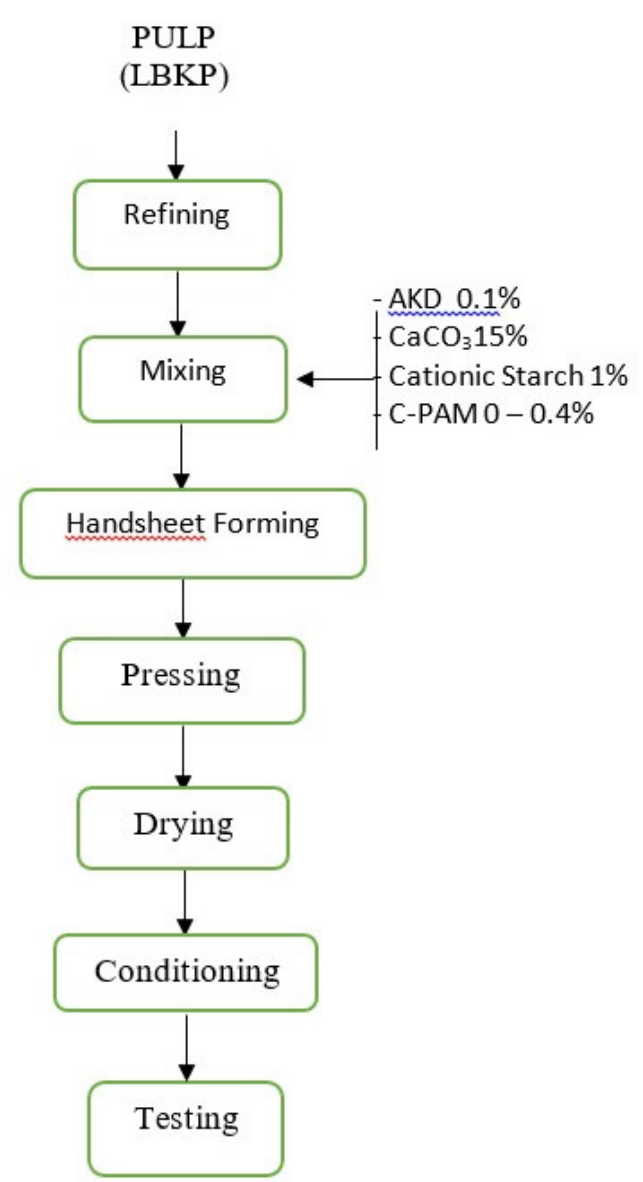

Figure 2. Diagram of laboratory handsheet making

\section{Results and Discussion}

$3.1 \mathrm{pH}$

$\mathrm{pH}$ of paper is defined as negative logarithmic of hydrogen ion concentration in water extract of paper, measured at standard condition. $\mathrm{pH}$ value is responsible for paper permanence especially for archive paper. The test results showed the $\mathrm{pH}$ value were 7.0, 8.0, 8.4, 8.4 and 8.5respectively, for blank, C-PAM 0.1, 0.2, 0.3 and 0.4\% (Figure 3).

Acid paper tends to deteriorate very rapidly; perhaps not more than 50 years. That's why the alkaline paper is also called as acid-free paper, i.e the paper with more than 7 of $\mathrm{pH}$ (http://printwiki.org/Alkaline Paper).

Based on its' $\mathrm{pH}$, there are 3 types of permanent paper. Type $\mathrm{I}$ is paper with maximum permanence with the $\mathrm{pH}$ of 7.5-9,5. The second type is high permanent paper with the $\mathrm{pH}$ of 6.5-8.5; while the third type is medium permanent paper with the $\mathrm{pH}$ of greater than 5.5 (https://books.google.co.id/books?id=7A5baiivedkC\&pg=PA107\&lpg=PA107\&dq=effect + of + pH + on + paper + pe rmanence\&source=bl\&ots $=$ VdHT1xQu0w\&sig $=$ ACfU3U3uYsLbqpx4fCsxDLJerdozUfwL8A\&hl=id\&sa $=X \& v$ ed=2ahUKEwj9mbLChOLpAhVmH7cAHX_CC1cQ6AEwG3oECAwQAQ\#v=onepage\&q $=$ effect $\% 20 \mathrm{of} \% 20 \mathrm{pH}$ $\% 20$ on $\% 20$ paper\%20permanence \&f=false)

Table 1. The influence of C-PAM to the $\mathrm{pH}$

\begin{tabular}{ccc}
\hline AKD $(\%)$ & C-PAM $(\%)$ & $\mathrm{pH}$ \\
\hline 0.1 & 0 & 7.0 \\
0.1 & 0.1 & 8.0 \\
0.1 & 0.2 & 8.4 \\
0.1 & 0.3 & 8.4 \\
0.1 & 0.4 & 8.5 \\
\hline
\end{tabular}




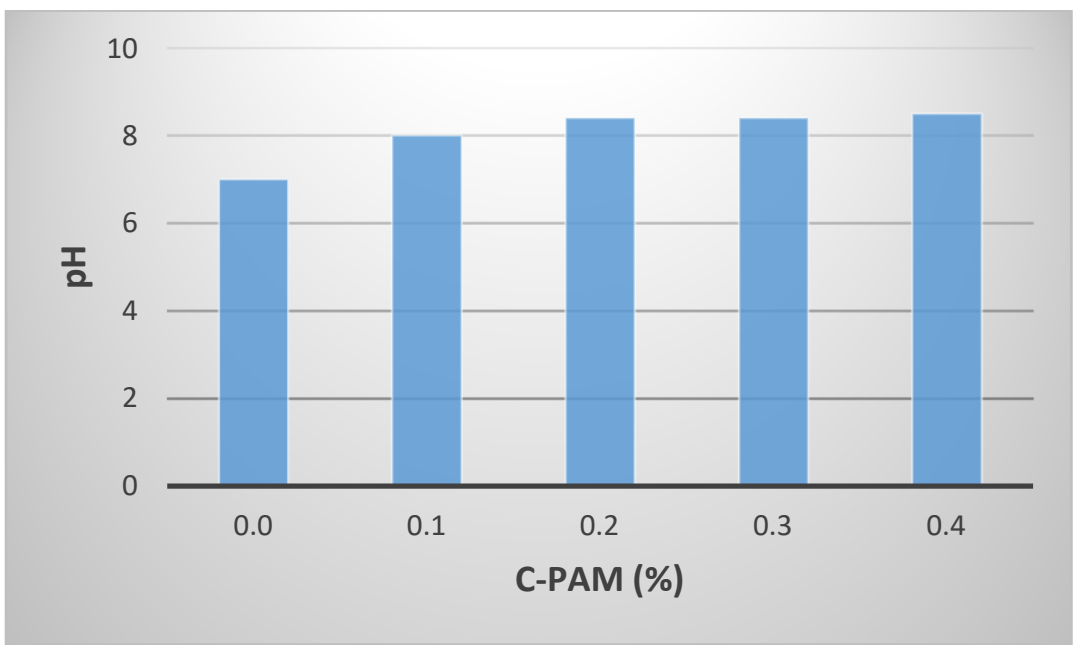

Figure 3.The influence of C-PAM to the $\mathrm{pH}$

\subsection{Water Absorptivity or Cobb Size}

Water absorptivity or Cobb size $\left(\mathrm{Cobb}_{60}\right)$ is the amount of water in grams which can be absorbed by $1 \mathrm{~m}^{2}$ of paper or paperboard, measured at standard condition. The lower absorption value means the higher the water penetration resistance of the sheets. Water absorptivity is one of important properties for printing and writing papers. The test results showed that the water absorptivity value are $160,21.0,19.0,18.5$ and $18.5 \mathrm{~g} / \mathrm{m}^{2}$ respectively, for blank, CPAM 0.1, 0.2, 0.3 and $0.4 \%$ (Figure 4).

\begin{tabular}{ccc}
\multicolumn{3}{c}{ Table 2 . The influence of C-PAM to the water absorptivity } \\
\hline AKD $(\%)$ & C-PAM $(\%)$ & Water Absorptivity $\left(\mathrm{g} / \mathrm{m}^{2}\right)$ \\
\hline 0.1 & 0 & 160.0 \\
0.1 & 0.1 & 21.0 \\
0.1 & 0.2 & 19.0 \\
0.1 & 0.3 & 18.5 \\
0.1 & 0.4 & 18.5 \\
\hline
\end{tabular}

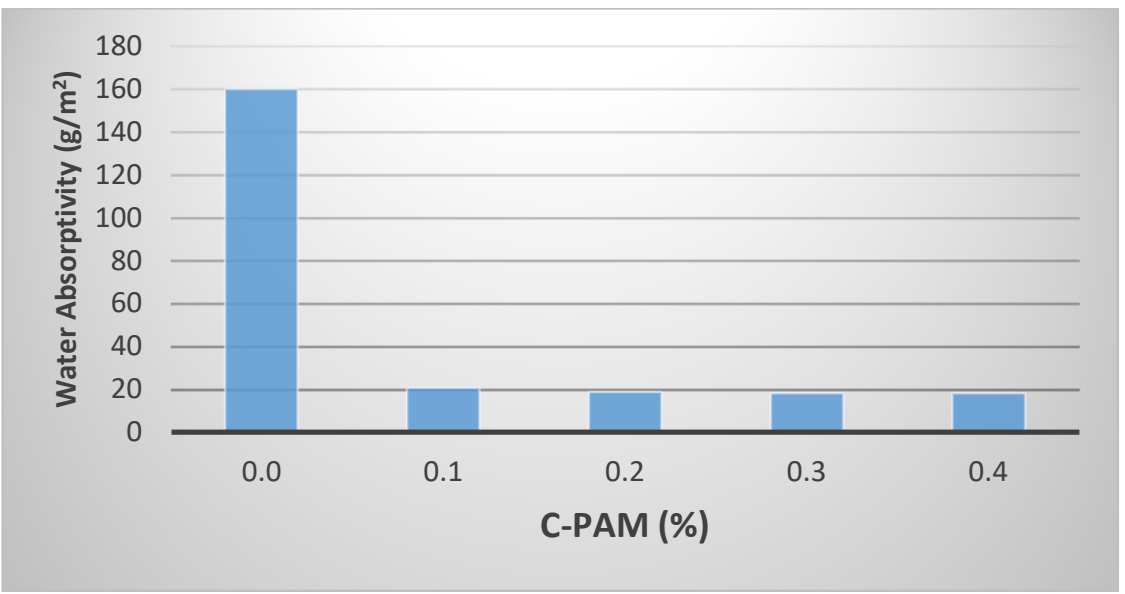

Figure 4. The influence of C-PAM to the water absorptivity

Cationic polyacrylamide were expected to promote the AKD sizing efficiency through facilitating deposition of AKD on to the anionic fibers for cationic polyelectrolyte can bond with the electronegativity points on AKD emulsion particles and improve the positive charges on between cellulosic fibers and AKD emulsion. In addition, cationic polyacrylamide will neutralize the anionic components in the pulp to avoid positive charges on AKD emulsion particles being consumed (Isogai, A.,et al1997 ;Jian, L.et al 2006).

\subsection{Tensile Index}

Tensile strength is one of the basic strength properties tested on pulp and paper. As expected, the Cationic polyacrylamide significantly increased the tensile strength of the paper.

The test results showed that the tensile index value are 14.0, 19.0, 19.5, 20.0 and $20.5 \mathrm{~g} / \mathrm{m}^{2}$ respectively,for blank, C-PAM 0.1, 0.2, 0.3 and 0.4\% (Figure 5). 
The tensile index of the pulp is independent of chemical properties and is very much dependent on the bonding ability of the fibers in the network (A. Ashori, 2006).

Table 3. The influence of C-PAM to the tensile index

\begin{tabular}{ccc}
\hline AKD $(\%)$ & C-PAM $(\%)$ & Tensile Index $(\mathrm{Nm} / \mathrm{g})$ \\
\hline 0.1 & 0 & 14.0 \\
0.1 & 0.1 & 19.0 \\
0.1 & 0.2 & 19.5 \\
0.1 & 0.3 & 20.0 \\
0.1 & 0.4 & 20.5 \\
\hline
\end{tabular}

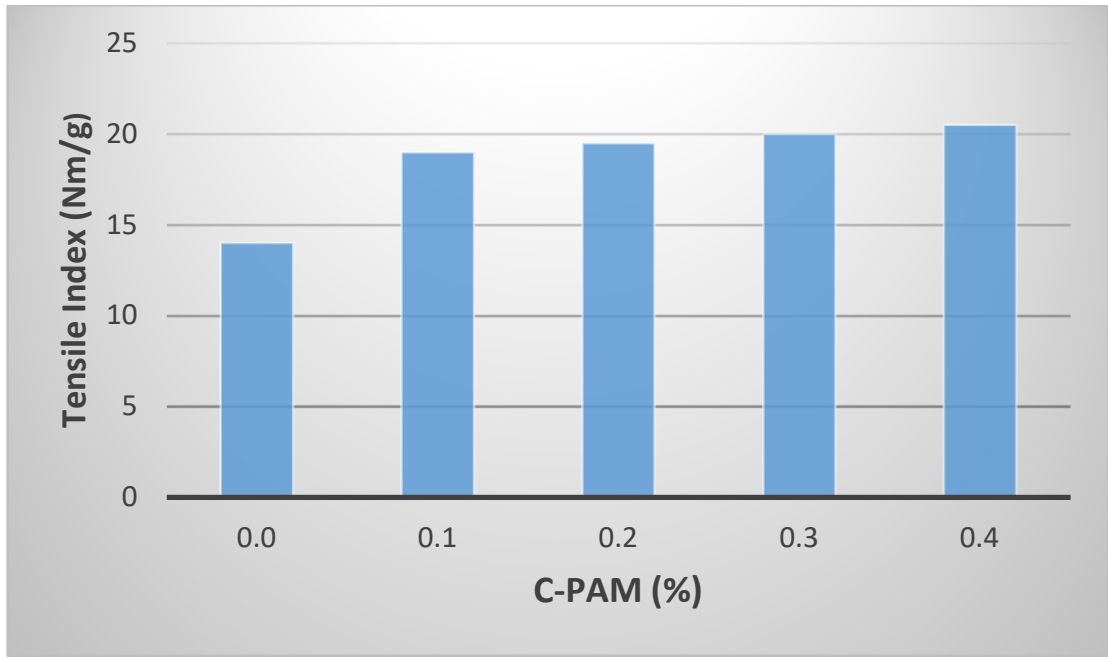

Figure 5. The influence of C-PAM to the tensile index

\section{Conclusion}

The usage of cationic polyacryalmide (C-PAM) as a retention aid for alkaline paper sized by alkylketene dimer (AKD) improved the resistance of paper to liquid penetration as well as the tensile strength of paper.

\section{Acknowledgement}

Gratitude is delivered to the Director of Center for Pulp and Paper, Ministry of Industry, who has given his supports up to this paper completed and submitted to be published.

\section{References}

Isogai, A., Kitaoka, C., Onabe, F., 1997: Effect of carboxyl groups on pulp on the retention of alkyl ketene dimmer. Journal of pulp and paper science 23(5): 215-219.

L. Neimo, (1999) :Papermaking Chemistry, L. Neimo, Ed., FapetOy, Helsinki, Finland, 95-151.

Jian, L. I., Sheng, W. G, Shan, C, F., 2006: Characteristics of high charge density cationic polyamine adsorption on pulp fibers and the effects of the adsorption on pulp properties, China Pulp \& Paper 25(10): 4-7.

Lindström, T., Glad-Nordmark, G., 2007: A study of AKD-size retention, reaction and sizing efficiency. Part 4: The effects of $\mathrm{pH}$, bicarbonate and metal ions on AKD-hydrolysis, Nordic Pulp \& Paper Research Journal 22(2): 167-171.

Shan, Y. Yi., Fu, Y., Juan, Q., Meng, H., 2012: Synthesis of star cationic polyacrylamide and its application in the retention and drainage system of papermaking, Advanced Materials Research 476-478: 2256-2259.

Casey, J.P., Pulp and Paper, Vol. 3, $3^{\text {rd }}$ ed., John Wiley and Sons, New York, 1981.

Jin, W., Chen, 2003: Application of cationic polyacrylamide as retention and drainage aids in bleached wheat straw pulp, Transactions of China Pulp \& Paper.

Johansson J, Lindström T. 2004: A study on AKD-size retention, reaction and sizing efficiency Part 1: The effects of pulp bleaching on AKD-sizing, Nordic Pulp \& Paper Research Journal 19(3): 330-335.

Johansson., 2004: A Study on AKD-size retention, reaction and sizing efficiency. Part 2: The effects of electrolytes, retention aids, shear forces and mode of addition on AKD sizing, Nordic Pulp \& Paper Research Journal 19(3): 336-344.

Vanerek, A, Alince, B., Ven, T. D., 2000: Interaction of calcium carbonate fillers with pulp fibers: Effect of surface charge and cationic polyelectrolytes, Journal of Pulp \& Paper Science 26(9): 317-322.

Jeremo M. Gess and Paul H. Wilson 2007: TAPPI PRESS 15 Technology Parkway South Norcross, GA 30092 
U.S.A. www.tappi.org

Marton, J., 1991: Practical Aspects of Alkaline Sizing, Alkyl Ketene Dimer in Mill Furnishes, Tappi Journal 74(8) : $187-191$.

Antunes, E.; Garcia, F.A.P.; Ferreira, P.; Blanco, A.; Negro, C.; Rasteiro, M.G., 2008 : Use of new branched cationicpolyacrylamides to improve retention and drainage in papermaking. Ind. Eng. Chem. 47,9370-9375.

Hubbe, M.A., 2005: Acidic and alkaline sizings for printing, writing and drawing papers, The Book and Paper Annual (23): 139-151

http://printwiki.org/Alkaline_Paper, Accessed at June 02, 2020

https://books.google.co.id/books?id=7A5baiivedkC\&pg=PA107\&lpg=PA107\&dq=effect + of + pH + on + paper + per manence\&source $=$ bl\&ots $=\mathrm{VdHT} 1 \mathrm{xQu} 0 \mathrm{w} \& \mathrm{sig}=\mathrm{ACfU} 3 \mathrm{U} 3 \mathrm{uYsLbqpx} 4 \mathrm{fCsxDLJerdozUfwL} 8 \mathrm{~A} \& \mathrm{hl}=\mathrm{id} \& \mathrm{sa}=$ X\&ved=2ahUKEwj9mbLChOLpAhVmH7cAHX_CC1cQ6AEwG3oECAwQAQ\#v=onepage\&q=effect $\% 2$ 0of\%20pH\%20on\%20paper\%20permanence \&f=false, Accessed at June 02, 2020

H.L. Lee and P. Luner, Nord., 2005 : Pulp Paper Res. J., 227-231

Song et al., 2012 : Sizing efficiency through AKD depends on several factors including retention, www.researchgate.net $>$ publication $>279926416$ Effect_..

D.B. Evans W.F. Reynolds (Ed.), 1989 : The Sizing of Paper (2nd ed.), Tappi Press.

A. Ashori., 2006 : Pulp and Paper from Kenaf Bast Fiber. Faibers and Polymers, 7(1), 26-29 